\title{
Numerical Study on Cavitation Noise of Symmetrical Blade Submarine Propeller
}

\author{
Agung Purwana ${ }^{1, \mathrm{a}, *}$, Wisnu Wardhana ${ }^{2, \mathrm{~b}}$, I Made Ariana ${ }^{1, \mathrm{c}}$ and Dhimas Widhi $\mathbf{H}^{1, \mathrm{~d}}$ \\ ${ }^{1}$ Department of Marine Engineering, Institut Teknologi Sepuluh Nopember, Surabaya, Indonesia \\ ${ }^{2}$ Department of Ocean Engineering, Institut Teknologi Sepuluh Nopember, Surabaya, Indonesia \\ a.agpurwana@gmail.com, b.wisnuwardhana2@yahoo.com, c.ariana@its.ac.id,d. \\ dhimas_mareng@yahoo.com \\ *corresponding author
}

Keywords: $\quad$ Numerical study, submarine propeller, cavitation noise.

\begin{abstract}
Radiated underwater noise is a signature of requirements related to survival in carrying out missions and concerns about marine environmental issues. On submarine propulsion system, the noise is resulted by propeller cavitation. In this study, numerical simulations with MRF (multiple reference frame) techniques are used to predict cavity and cavitation noise around propellers. The formulation of Reynold Averaged Navier Stokes with turbulence model k-omega Shear Stress Transport and Fast Fourier Transform is applied on the simulation. The far-field radiation at different operating conditions is calculated by the FW-H (Ffowcs Williams-Hawkings) equation. The effect of rotation and skew propeller angles on the shape and area of cavity and cavitation noise are simulated. Noise characteristics are presented according to different positions of hydrophones and speeds of the propeller. 3D model of symmetrical blade propeller in $\mathrm{D}=200 \mathrm{~mm}$, blade number $\mathrm{Z}=7$, pitch diameter ratio $\mathrm{P} / \mathrm{D}=0.816$, area ratio $\mathrm{Ae} / \mathrm{Ao}=0.88$, skew angle 54 degree, is simulated on various propeller rotation and advance coefficient $(\mathrm{J})$.
\end{abstract}

\section{Introduction}

The propeller for propulsion must be carefully designed in accordance with the specific vessel. The design and development of propeller for submarine has a difference from the propellers for surface vessels. The most important requirement is low noise as well as propeller efficiency, so submarine propeller must be optimized in terms of noise and efficiency. Survivability of submarines in underwater detection is strongly influenced by sounds generated by propellers.

In this paper, we considered only cavitating marine propeller induced noise and propeller cavity using numerical simulation. Researchers specifically investigated the performance and noise of marine propellers using numerical simulations such as: Ffowcs Williams-Hawkings (FWH) [1] published acoustic predictions with the method for calculation noise an arbitrary body moving in a fluid are still adopted in hydro-acoustics predicted by this available method in computational numerical practice. Non-cavitation noise of underwater propeller is numerically investigated using time-domain acoustic analogy and boundary element method and Ffowcs Williams-Hawkings 
formulation to predict the far field acoustics. Noise prediction results are presented for single propeller and ducted propeller by Seol et.al. [2]. Seol et.al [3] presents a numerical study on the noncavitating and blade sheet cavitation noises of the underwater propeller is predicted using timedomain acoustic analogy and .Ffowcs Williams-Hawkings formulation to predict the far-field acoustics. Salvatore and Ianniello [4] published and predicted from cavitation sheet propeller noise transiently with hydrodynamic model coupled with a hydro-acoustics model in non-uniform inviscid flow based on the Fflwcs Williams-Hawkings equation corresponding to the Bernoulli equation model. Barbarino and Casalino [5] predicted and validated analytically and numerically for the trailing-edge noise spectrum in the frequency domain from a flat plate from a NACA-0012 airfoil. M.Ozden et.al. [6] investigated a numerically for the INSEAN E1619 submarine propeller radiated noise in open water and behind a generic DARPA suboff using Reynolds Averaged Navier-Stokes (RANS) and Ffowcs Williams-Hawking equation. Kawamura et.al. [7] comparatively investigated different turbulence models for the prediction of open water performance for a conventional propeller. $\mathrm{Li}$, [8] estimated open water characteristics of a highly skewed model propeller employing $\mathrm{k}-\omega$ turbulence model and validated the study with experimental data. The cavitation phenomenon of the sheet in the form of a large bubble on the surface of the propeller blade generates low frequency noise by forming regions I and II in the general sound spectrum of the cavitation propeller described in the figure. 1. It is important to analyze accurately in cavitation sounds that are the main source of propeller noise. [3].

This study presents a numerical study on noises of the underwater submarine propeller for different performance conditions. This paper have carried out for the prediction of cavity and noise propeller cavitation characteristics of submarine propeller using numerical simulation. The blade cavitation noise generated by an underwater submarine propeller is analyzed numerically. The method used for the noise prediction is given in chapter II.

\section{Numerical Simulation}

\subsection{Method}

This work is carried out using numerical simulation, which has a built-in marine propeller hydrodynamic performance coefficient $(\mathrm{KT}, \mathrm{Kq}, \eta)$ corresponding to advance coefficient $(\mathrm{J})$ and Reynolds number $(\mathrm{Re})$ equation.

$$
\begin{aligned}
& J=\frac{V_{a}}{N D} K_{T}=\frac{T}{\rho N^{2} D^{4}} K_{Q}=\frac{Q}{\rho N^{2} D^{5}} \eta=\frac{K T . J}{K Q .2 \pi}=\frac{T V_{a}}{2 \pi n Q} \\
& \left(R_{e}\right)_{0.75 R}=\frac{C_{0.75 R^{*}} \sqrt{\left[V_{a}^{2}+(0.75 \pi n D)^{2}\right]}}{v} \\
& \sigma=\frac{P_{o}-P_{v}}{0.5 \rho N^{2} D^{2}}
\end{aligned}
$$

where T, Q, N, D, $\rho, \mathrm{V}$ and Re are the propeller thrust, torque, rotational speed, diameter, water density and advance velocity, and Reynold number of a characteristicradius (0.75R) respectively. In present paper, the flow field is analyzed with finite volume method (FVM) and the propeller computational domain is cylindrical shape surrounding the propeller where a rotational cylinder with sufficient larger diameter than the propeller diameter enfolds the propeller in its cross section center and allows the fluid to pass by the model. The rotating zone was solved via Moving Reference Frame (MRF) which is shown in Figure 3 and 4, and then the time dependent flow field data are used as the input for Ffowcs Williams-Hawkings formulation to predict the far-field acoustics. 
The noise characteristics are predicted and calculated according to the conditions and noise sources. The developed flow solver is applied to the model propeller in uniform inflow. The simulation has been carried out by using the FW-H formulation (Ffowcs Williams Hawkings Equation) as discussed earlier. The Navier-Stokes and continuity equation have been manipulated and derived into FW-H Equations for nonhomogeneous wave equations [9]. For the numerical calculations was used to satisfy the following governing equation for continuity:

$$
\frac{\partial \rho}{\partial t}+\frac{\partial}{\partial x_{i}}\left(\rho v_{i}\right)=0
$$

where $x_{i}$ and $v_{i}$ are the tensor form of velocities and axial coordinates. And the momentum equation becomes:

$$
\frac{\partial\left(\rho v_{i}\right.}{\partial t}+\frac{\partial\left(\rho u_{i} u_{j}\right)}{\partial x_{j}}=-\frac{\partial p}{\partial x_{i}}+\frac{\partial}{\partial x_{j}}\left[\mu\left(\frac{\partial u_{i}}{\partial x_{j}}+\frac{\partial u_{j}}{\partial x_{i}}-\frac{2}{3} \delta_{i j} \frac{\partial u_{l}}{\partial x_{l}}\right)\right]+\frac{\partial}{\partial x_{j}}\left(-\rho \overline{u_{i}^{\prime} u_{j}^{\prime}}\right)
$$

where is $\delta_{i j i s}$ Kronecker Delta and $-\rho \overline{u_{i}{ }^{\prime} u_{j}{ }^{\prime}}$ are the unknown Reynolds stresses.

$\left.\left.\rho\left(u_{n}-v_{n}\right)\right] \delta(f)\right\}$

$$
\frac{1}{a_{0}^{2}} \frac{\partial^{2} p^{\prime}}{\partial t^{2}}-\nabla^{2} p^{\prime}=\frac{\partial^{2}}{\partial x_{i} \partial x_{j}}\left\{T_{i j} H(f)\right\}-\frac{\partial}{\partial t}\left\{\left[P_{i j} n_{j}+\rho u_{i}\left(u_{n}-v_{n}\right)\right] \delta(f)\right\}+\frac{\partial}{\partial t}\left\{\left[\rho_{0} v_{n}+\right.\right.
$$

$P_{i j}$ is compressive stress tensor, $p^{\prime}$ is sound pressure at the far-filed $\left(p^{\prime}=p-p 0\right) . \mathrm{H}(\mathrm{f})$ is Heaviside function, Tij is Lighthill stress tensor, $v_{i}$ is surface velocity component in the $x_{i}$ direction, $v_{n}$ is surface velocity component normal to the surface $u_{i}$ is fluid velocity component in the $x_{i}$ direction, $u_{n}$ is fluid velocity component normal to the surface $\mathrm{f}=0, \delta(f)$ is Dirac delta function, The solution to above Equation is obtained using the free-space Green's function. For the study of turbulence modeling with good performance on wall bounded flow limit layer used turbulence model of SST k- $\omega$. [8]

Computational methods for cavitation flows can be largely categorized into two groups: singlephase modelling with cavitation interface tracking and multi-phase modelling with an embedded cavitation interface. The former approach has been widely adopted for inviscid flow solution methods and mixture equation solvers. In this paper is used of multi-phase model. The cavitation model employed in the present study was introduced by Schnerr-Sauer-Yuan [10]. This model is based on the approach that the mixture contains a large number of spherical bubbles. The mass exchange rate is then based on a simplified model for bubble growth based on the Rayleigh-Plesset equation. It should therefore account for non-equilibrium effects.

$$
R_{e}=\frac{\rho_{v} \rho_{l}}{\rho_{m}} \alpha(1-\alpha) \frac{3}{R_{B}} \sqrt{\frac{2}{3} \frac{\left(p_{v}-p\right)}{\rho_{l}}}
$$

$$
R_{c}=\frac{\rho_{v} \rho_{l}}{\rho_{m}} \alpha(1-\alpha) \frac{3}{R_{B}} \sqrt{\frac{2}{3} \frac{\left(p-p_{v}\right)}{\rho_{l}}}
$$

With $\mathrm{Rb}$ being the bubble radius given as:

$$
R_{B}=\left(\frac{\alpha}{1-\alpha} \frac{3}{4 \pi} \frac{1}{n_{b}}\right)^{\frac{1}{3}}
$$

The only constant which has to be determined is the number of vapor bubbles per volume of liquid (n). As stated by Weixing Yuan, Jürgen Sauer, and Günter H.Schnerr [11], a value of 1.51014 nuclei $/ \mathrm{m}^{3}$ water yields good agreement with experimental observation of P.Roosen, O.Unruh, and M. Behmann. [12]. 
In the present calculation, we used unsteady numerical simulation via Coupled algorithm with second order implicit pressure based solver. Least Squares Cell Based is used for gradient and PRESTO for pressure discretization. The k- $\omega$-SST model was used, and second order upwind scheme was selected as the discretization scheme in all cases for cavitating turbulent flows around a highly skewed model marine propeller has been conducted to predict the propeller performance.

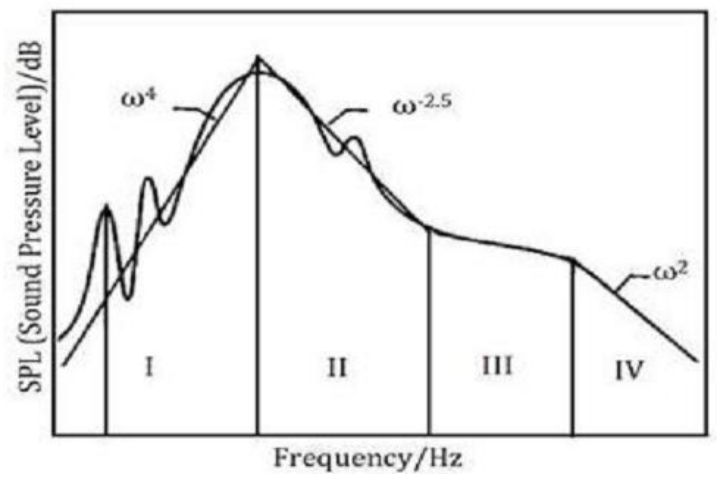

Figure 1: The frequency ranges of cavitation noise for marine propellers (Seol, 2005)[12].

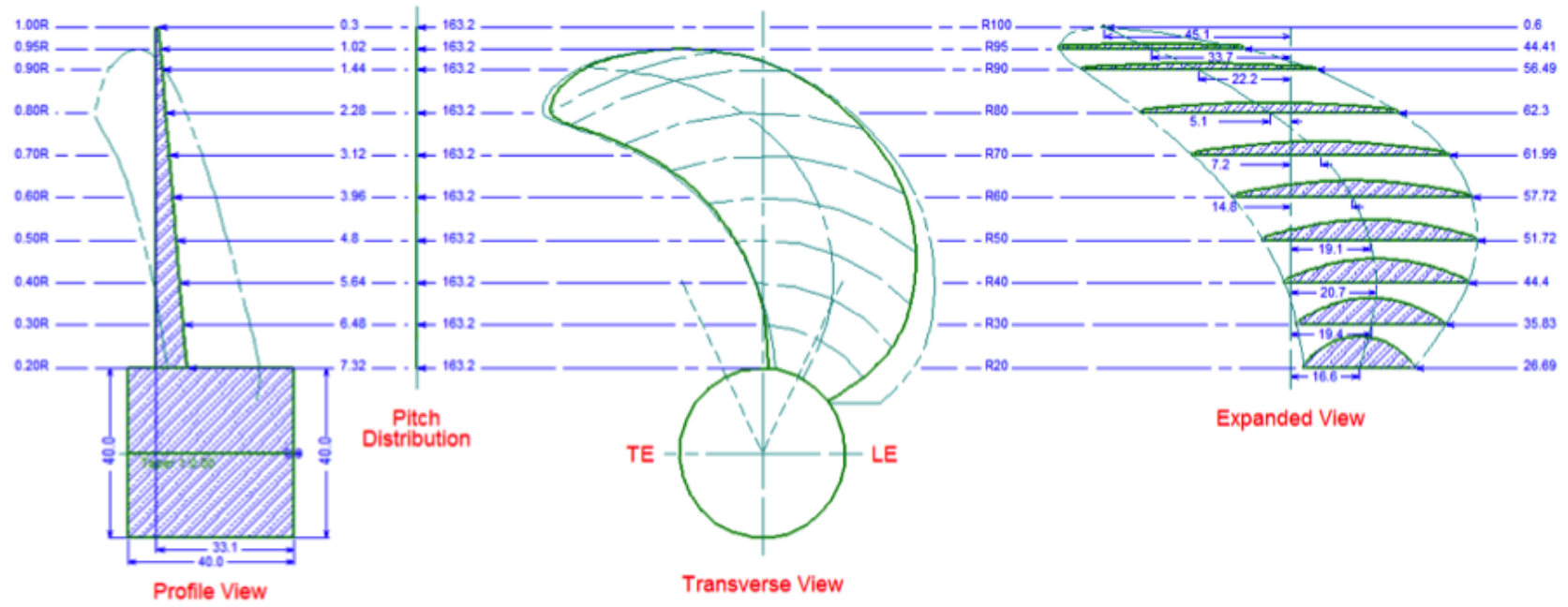

Figure 2: 2D model symmetrical blade propeller skew 54 degree

\subsection{Symmetrical Blade Propeller}

The symmetrical blade propeller has been numerically calculated in open water condition. The Open water experiments were implemented in the IHL (Indonesia Hydrodynamic Laboratory) towing tank. Results were presented by Nurwidhi.A et.al [13]. Propeller data and 2D models of the propeller are can be seen in the Table I and Figure 2. In Figure 3 the detailed mesh used for the study is presented.

In modeling the fluid homogeneous flow for the propeller is numerically divided into dynamic and static cylinders, as illustrated in Figures 4. Using the Coriolis acceleration term in the fluid arrangement equation, the dynamic frame is simulated by propeller rotation. The diameter of the propeller (D) is used as reference relating to the frame dimension. The size of the static frame diameter is $3 \mathrm{D}$ with an overall length of $7 \mathrm{D}$, with a distance of $2 \mathrm{D}$ from the inlet side and $5 \mathrm{D}$ from the outlet side. The size of the computational simulation domains in this study is used based on our previous work and some other numerical simulation works on marine propellers. 
Table 1: Propeller data.

\begin{tabular}{|l|l|}
\hline \multicolumn{2}{|c|}{ Propeller Data } \\
\hline Number of blades $(\mathrm{Z})$ & 7 \\
\hline Diameter $(\mathrm{mm})$ & $0.20 \mathrm{~m}$ \\
\hline Hub/Diameter Ratio & 0.21 \\
\hline Expanded blade area Ratio ( Ae/A0) & 0.88 \\
\hline Pitch at r=0.7R P/D) & 0.816 \\
\hline Rake & 0 degrees \\
\hline Skew & 54 degrees \\
\hline Direction of rotation & Right handed \\
\hline
\end{tabular}

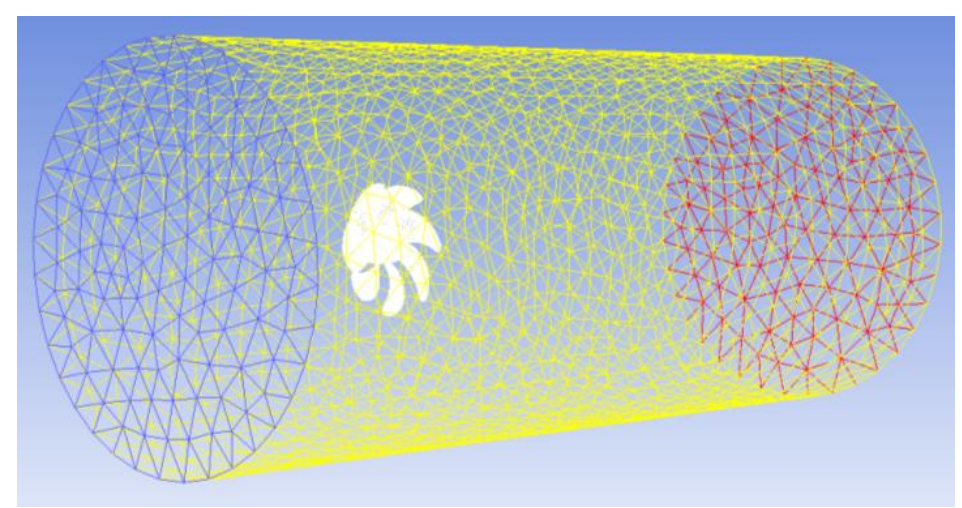

Figure 3: Geometry \& meshed model of the propeller with domain.

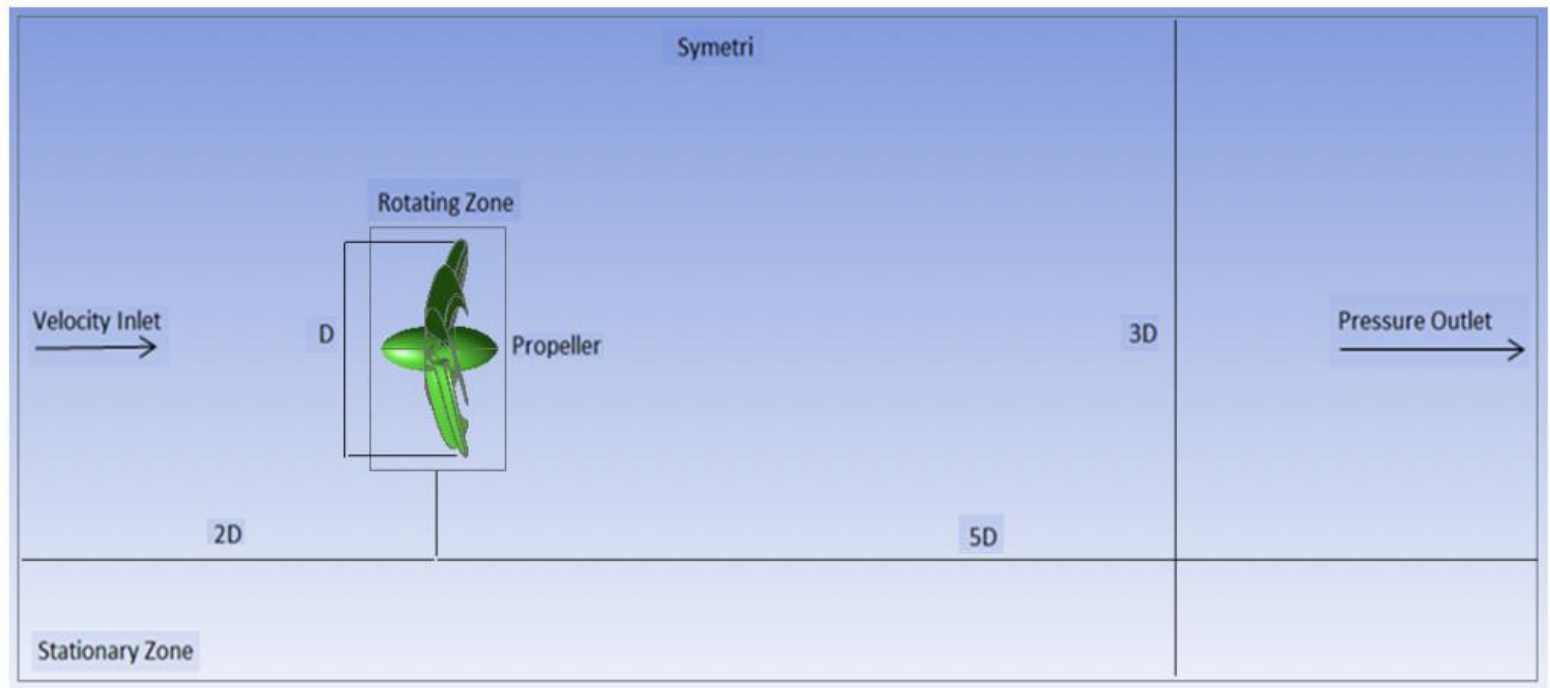

Figure 4: Computational domain around propeller (moving zone and stationary zone) and boundary conditions.

\subsection{Performance and Noise Prediction in Open Water}

Noise characteristics of propeller in open water condition was carried out transiently predicted at $\mathrm{J}=0.184-0.276,29-32 \mathrm{rps}$. Before the transient computations which were performed for the noise characteristic of propeller, calculation were carried out steady to predict the open water performance at $J=0.184-0.736,10.4 \mathrm{rps}$. In this study, we studied cavitating noise in order to find the ranges of the Sound Pressure Levels, its development and the effect of cavitation noise on the SPL's. In Table II, $\mathrm{N}$ is rotational speed, $\mathrm{Va}$ is axial velocity of flow, $\rho$ is density of water, ao is sound velocity and $\mathrm{P}$ ref is reference pressure in underwater. In this numerical simulation, 3 hydrophones are used for 
extracting the Sound Pressure Levels (SPLs). The Position of Hydrophones and their coordinates are shown in Figure.5 and Table III, respectively.

Table 2: Parameters of flow and acoustic conditions.

\begin{tabular}{|c|c|c|c|c|c|c|}
\hline $\mathrm{J}$ & $\mathrm{Va}(\mathrm{m} / \mathrm{s})$ & $\mathrm{N}(\mathrm{rps})$ & $\mathrm{Re}$ & ao $(\mathrm{m} / \mathrm{s})$ & Pref $(\mathrm{Pa})$ & Pressure $(\mathrm{Pa})$ \\
\hline 0.184 & 1.067 & 29 & $1.027 \mathrm{E}+05$ & 1500 & $10^{-6}$ & $50 \mathrm{kPa}$ \\
\hline 0.184 & 1.1776 & 32 & $1.196 \mathrm{E}+05$ & 1500 & $10^{-6}$ & $50 \mathrm{kPa}$ \\
\hline 0.276 & 1.601 & 29 & $1.906 \mathrm{E}+05$ & 1500 & $10^{-6}$ & $50 \mathrm{kPa}$ \\
\hline 0.276 & 1.7664 & 32 & $2.267 \mathrm{E}+05$ & 1500 & $10^{-6}$ & $50 \mathrm{kPa}$ \\
\hline
\end{tabular}

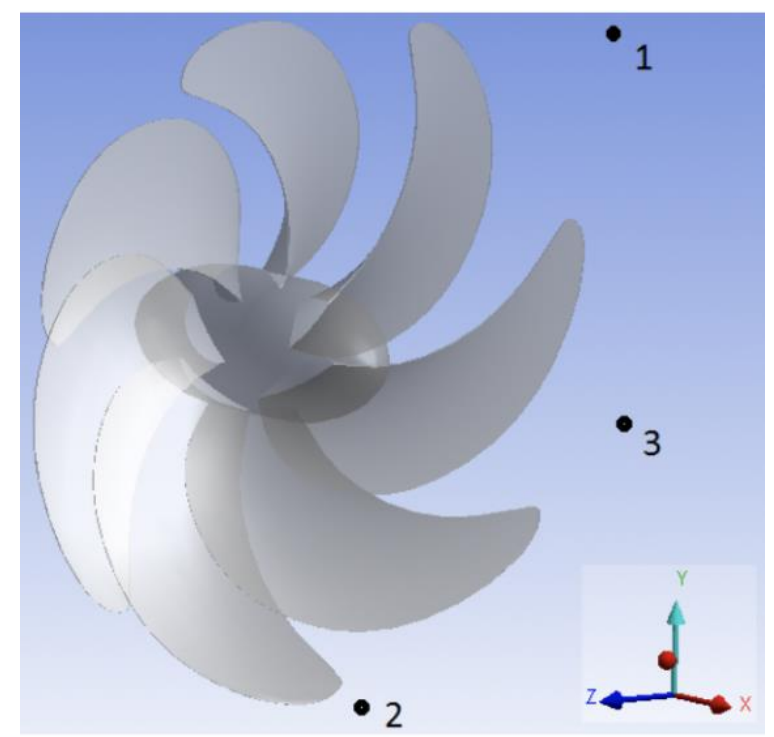

Figure 5: Position of hydrophones numerical simulation:

Table 3: Coordinates of hydrophones

\begin{tabular}{|l|l|l|l|}
\hline Name & X-Coord $(\mathrm{m})$ & Y-Coord $(\mathrm{m})$ & Z-Coord $(\mathrm{m})$ \\
\hline Hydrophone 1 & 1.0 & 0.375 & 0 \\
\hline Hydrophone 2 & 1.0 & 0 & 0.375 \\
\hline Hydrophone 3 & 1.0 & 0 & 0 \\
\hline
\end{tabular}

\section{Result and Discussion}

\subsubsection{Propeller Performances}

The predicted noise generated by the propeller is directly related to the precision for the pressure on the blade surface. Figures 6 shows the pressure distribution on propeller at an advance coefficient of $\mathrm{J}=0.184-10.4 \mathrm{rps}$. High pressure distribution occurs on the face side and low pressure occurs on the back side. Then, the contour path distribution of the axial flow velocity at upstream and downstream of the propeller at the $J=0.184$ coefficient of advance is shown in Figure 7 .

The values of thrust and torque at given advanced ratios calculated and captured very well using RANS equations. In Figure 8 shows the comparison of thrust and torque of the propeller with respect to the advance coefficient J. TABLE IV shows the comparison of thrust and torque of the propeller with respect to the advance coefficient $\mathrm{J}$. 


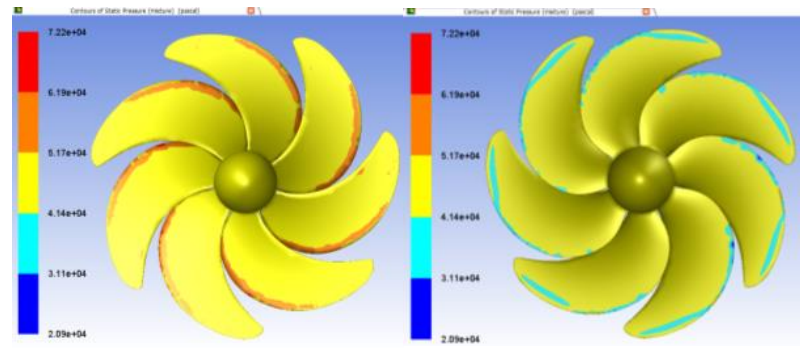

Figure 6: Pressure distribution on face (left) and back (right) of the propeller at $\mathrm{J}=0.184-10.4 \mathrm{rps}$.

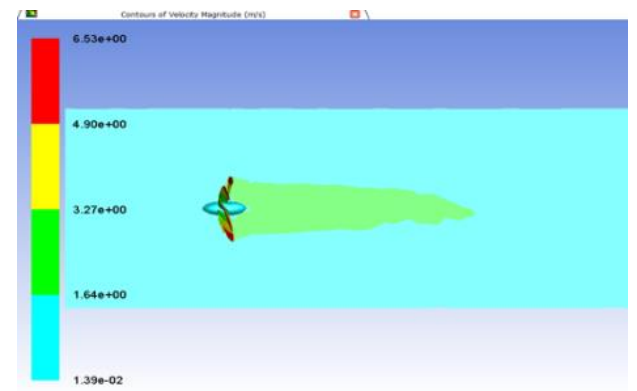

Figure 7: Axial velocity distribution in longitudinal plane atJ=0.184-10.4rps.

Table 4: The Numerical Simulation results with respect to the data simulation for propeller skew 54 degrees.

\begin{tabular}{|l|l|l|l|l|l|l|l|}
\hline \multirow{2}{*}{$\mathbf{J}$} & \multirow{2}{*}{$\mathbf{V a}(\mathbf{m} / \mathbf{s})$} & \multirow{2}{*}{$\mathbf{N}(\mathbf{r p s})$} & \multicolumn{5}{|l|}{ Simulation } \\
\cline { 4 - 8 } & & $\boldsymbol{T}(\boldsymbol{N})$ & $\boldsymbol{Q}(\mathbf{N m})$ & $\boldsymbol{K} \boldsymbol{1}$ & $\mathbf{1 0} \mathbf{K q}$ & $\boldsymbol{\eta}$ \\
\hline 0.184 & 0.3827 & 10.4 & 97.664 & 2.4158 & 0.5654 & 0.6993 & 0.2369 \\
\hline 0.184 & 1.067 & 29 & 535.77 & 14.905 & 0.3989 & 0.5548 & 0.2106 \\
\hline 0.184 & 1.1776 & 32 & 629.89 & 17.582 & 0.3852 & 0.5375 & 0.2099 \\
\hline 0.276 & 0.5741 & 10.4 & 85.22 & 2.1784 & 0.4933 & 0.6305 & 0.3439 \\
\hline 0.276 & 1.601 & 29 & 474.9 & 13.458 & 0.3536 & 0.501 & 0.3102 \\
\hline 0.276 & 1.7664 & 32 & 579.52 & 16.486 & 0.3543 & 0.5040 & 0.309 \\
\hline 0.368 & 0.7654 & 10.4 & 69.684 & 1.890 & 0.403 & 0.547 & 0.432 \\
\hline 0.46 & 0.9568 & 10.4 & 54.470 & 1.570 & 0.315 & 0.454 & 0.508 \\
\hline 0.552 & 1.1482 & 10.4 & 40.380 & 1.267 & 0.234 & 0.367 & 0.560 \\
\hline 0.644 & 1.3395 & 10.4 & 27.560 & 0.987 & 0.160 & 0.286 & 0.573 \\
\hline 0.736 & 1.5309 & 10.4 & 14.143 & 0.665 & 0.082 & 0.192 & 0.499 \\
\hline
\end{tabular}

The propeller blade with the effective angle of attack has a constant rotation characterized by the performance of thrust coefficient $\left(\mathrm{K}_{\mathrm{T}}\right)$ and the torque coefficient $\left(\mathrm{K}_{\mathrm{Q}}\right)$ decreases and reversely the advance coefficient increases. In figure. 8 and Table IV shows the numerical results for thrust and torque which have a good conformity with the data experimental in the range of the overall advance coefficient.

Cavitation on the propeller blades occurs vapor filled voids or bubbles in liquid (Figure 11-12) flowing due to a decrease in static fluid pressure around the propeller blades (Figure 9-10). 


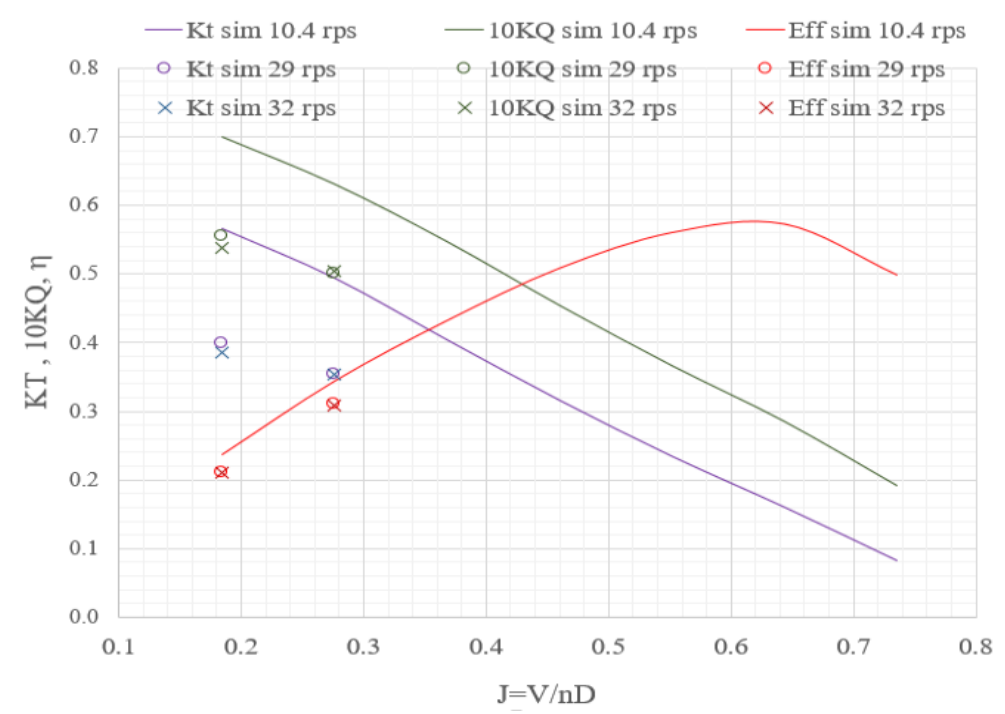

Figure 8: Comparison of thrust, torque and efficiency for propeller.

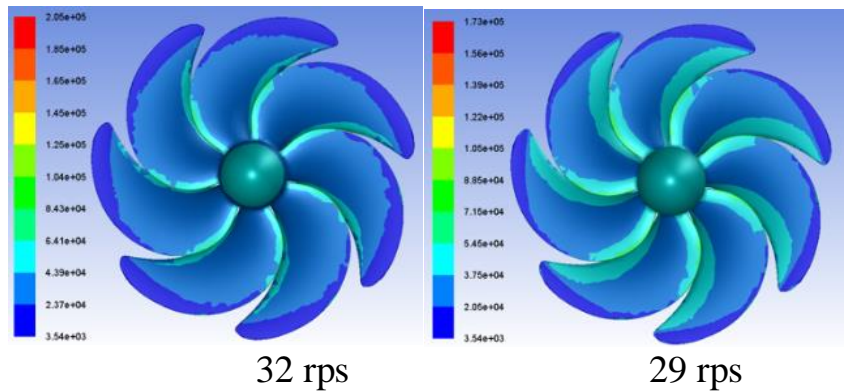

Figure 9: Pressure $(\mathrm{Pa})$ distribution on back side of the propeller 54 degree at $\mathrm{J}=0.184$.

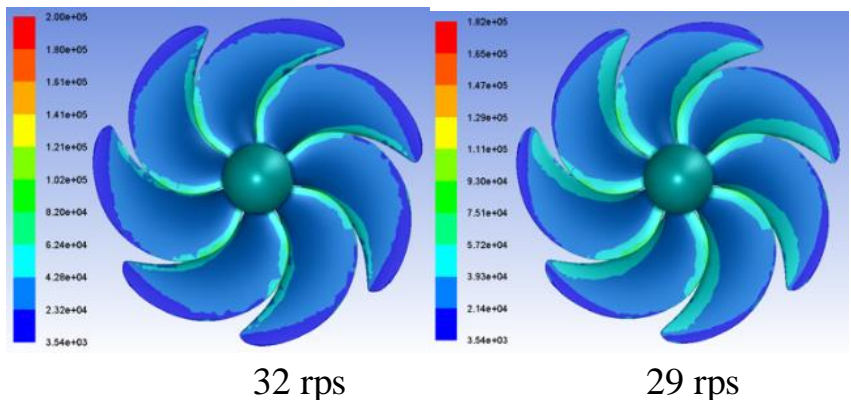

Figure 10: Pressure (Pa) distribution on back side of the propeller 54 degree at $\mathrm{J}=0.276$.

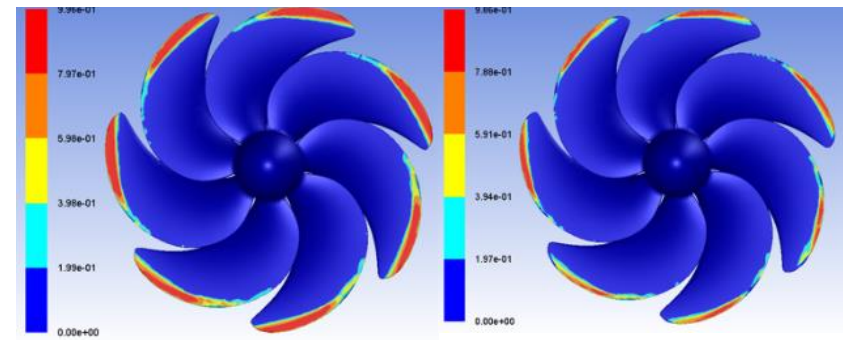

$32 \mathrm{rps}$

$29 \mathrm{rps}$

Figure 11: Volume fraction vapour distribution on back side of the propeller 54 degree at $\mathrm{J}=0.184$. 


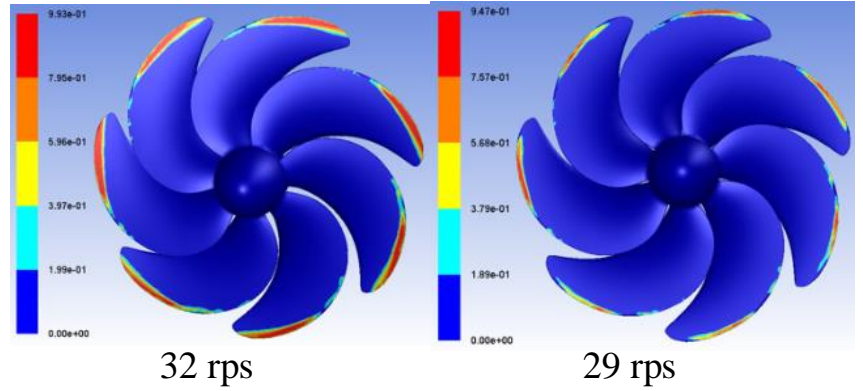

Figure 12: Volume fraction vapour distribution on back side of the propeller 54 degree at $\mathrm{J}=0.276$.

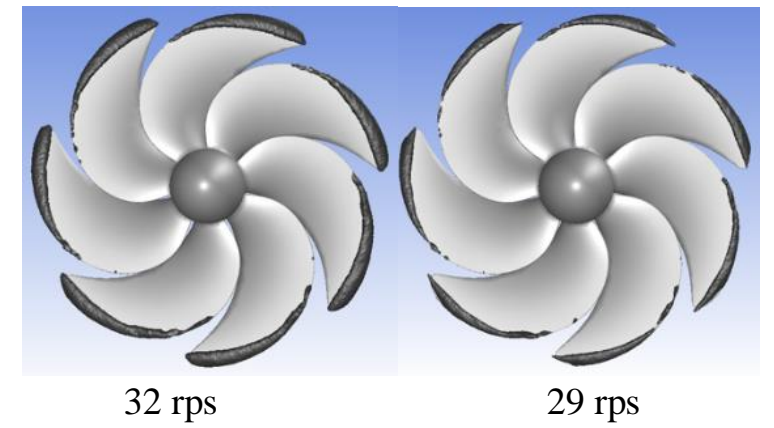

Figure 13: Iso surface volume fraction vapor 0.189 distribution on back side of the propeller at an advance coefficient of $\mathrm{J}=0.184,50 \mathrm{kPa}$.

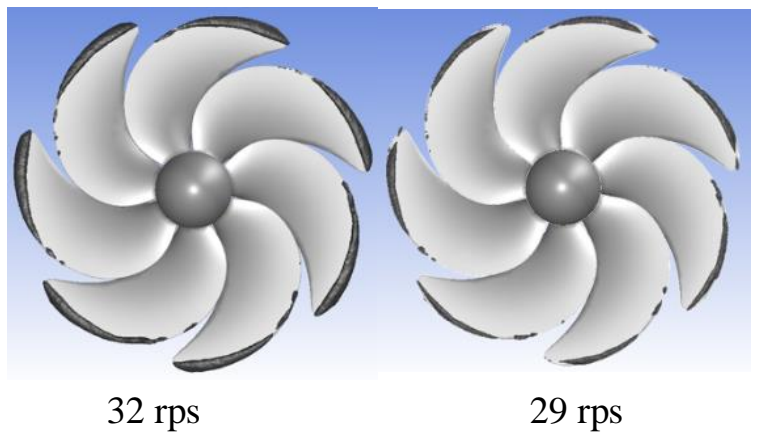

Figure 14: Iso surface volume fraction vapor 0.189 distribution on back side of the propeller at an advance coefficient of $\mathrm{J}=0.276,50 \mathrm{kPa}$.

Figures 11 and 12 shows the volume fraction vapor distribution on back side of the propeller at $\mathrm{J}=0.184$ and $\mathrm{J}=0.276$ at 29 and 32rps. Also, the iso surface volume fraction vapor 0.189 distribution on back side of the propeller at an advance coefficient of $\mathrm{J}=0.184$ and $\mathrm{J}=0.276$ at 29 and $32 \mathrm{rps}$ are shown in Figure.13 and 14. The potential of noise generated during the collapse of cavitation bubbles is examined in this paper. Cavitation with cavity size is proportional to the dimension of flow characteristics. The hydrodynamic or acoustic fluid pressure varies greatly and changes very rapidly during cavitation. Bubbles Water vapor Cavitation collapses are often changes and short lived and generates high-intensity acoustic pressure. When the maximum radius reaches the cavitation bubble is at a higher pressure area then the bubble becomes collapsed. The shock waves generated and an increase in bubble velocity that exceeds the speed of the sound of the fluid are the result of bubbles collapsing and explosions in the liquid.

Evaporated bubbles that are faster periods can produce more noise and damage than cavitation bubbles of gas containing non-condensing gases. Cavitation is not desirable on the marine propeller 
because it can cause damage to the surface of the blade, causing noise and vibration, and leads to a reduction in efficiency.

\subsubsection{Propeller Noise}

Noise characteristics are presented according to the noise sources and operation conditions of propeller. According to the results, cavitation noise is incepted by increasing of flow velocity and propeller rotation speed. The graph bellow represents the convergence history of the propeller sound pressure levels. The convergence criteria are considered as the difference between the values of the succeeding and preceding which are in the range of $1 \times 10^{-4}$.

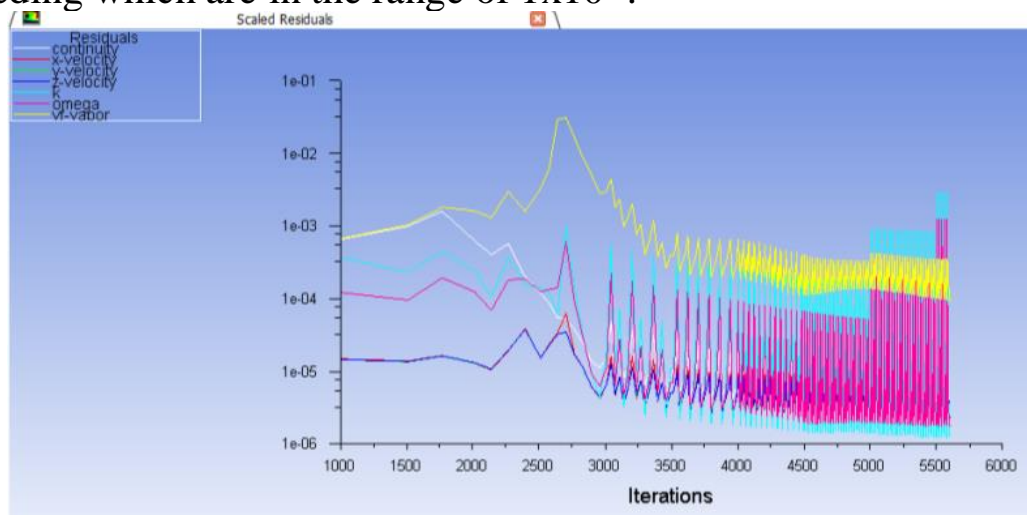

Figure 15: Convergence graph at $\mathrm{J}=0.184-32 \mathrm{rps}$

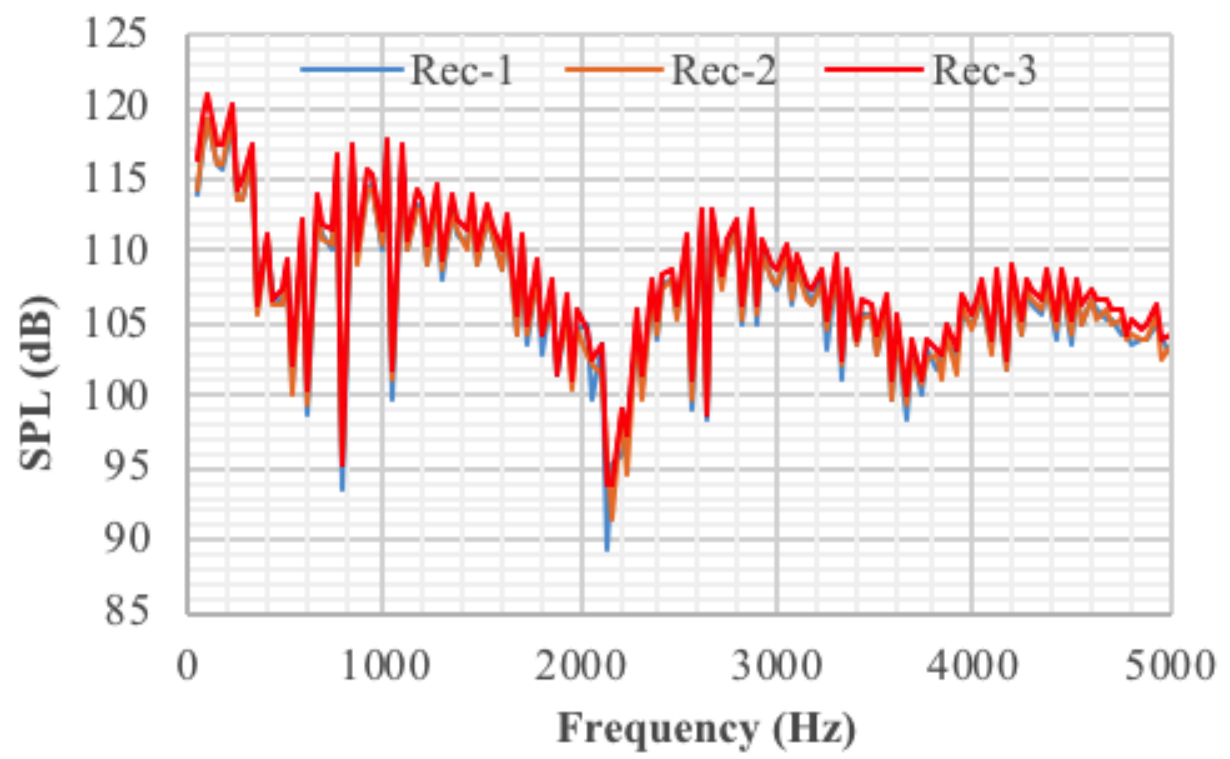

Figure 16: Noise prediction graph up to $5000 \mathrm{~Hz}$ (SPLs (dB) for receiver 1,2,3 at propeller, P ref $(\mathrm{Pa})=10^{-06}$ for $\mathrm{J}=0.184, \mathrm{~N}=32 \mathrm{rps}, 50 \mathrm{kPa}$

Acoustic graph in the following Figure 16 represents the Sound Pressure Level (SPLs) of the propeller resulted from various Receiver placed at various position for different operating condition flows velocity and rotational speed of propeller. As can be seen in the Figure 16, the SPL resulted on hydrophone 3 which is positioned in the x-axis is higher compared with the result of the SPL on hydrophones 1 and 2 which are positioned on the right and top side at j-0.184-32rps. This is because the turbulence and cavitation appear more significant in the position where the hydrophone 3 are located. 
The result of experiments shows that the SPL increase with the higher cavity at $\mathrm{J}=0.184-32 \mathrm{rps}$ as we can see in Figure 13 and 16.

This phenomenon is caused by the increasing of the rotational speed of the propeller. Higher rotational speed of propeller and the fluids that flows through the propeller cause turbulence and cavitation which generate a higher propeller noise. According Bernoulli's Law, the flow of the water through the propeller blades causes higher pressure in the face than in the back of propeller. As the rotation of propeller increases, this pressure difference becomes much higher. Low pressure induces bubbles as the result of boiling of water in the back of propeller. The bubbles are collapsed as it impacts to the back of propeller which significantly contribute to induce the noise of propeller.

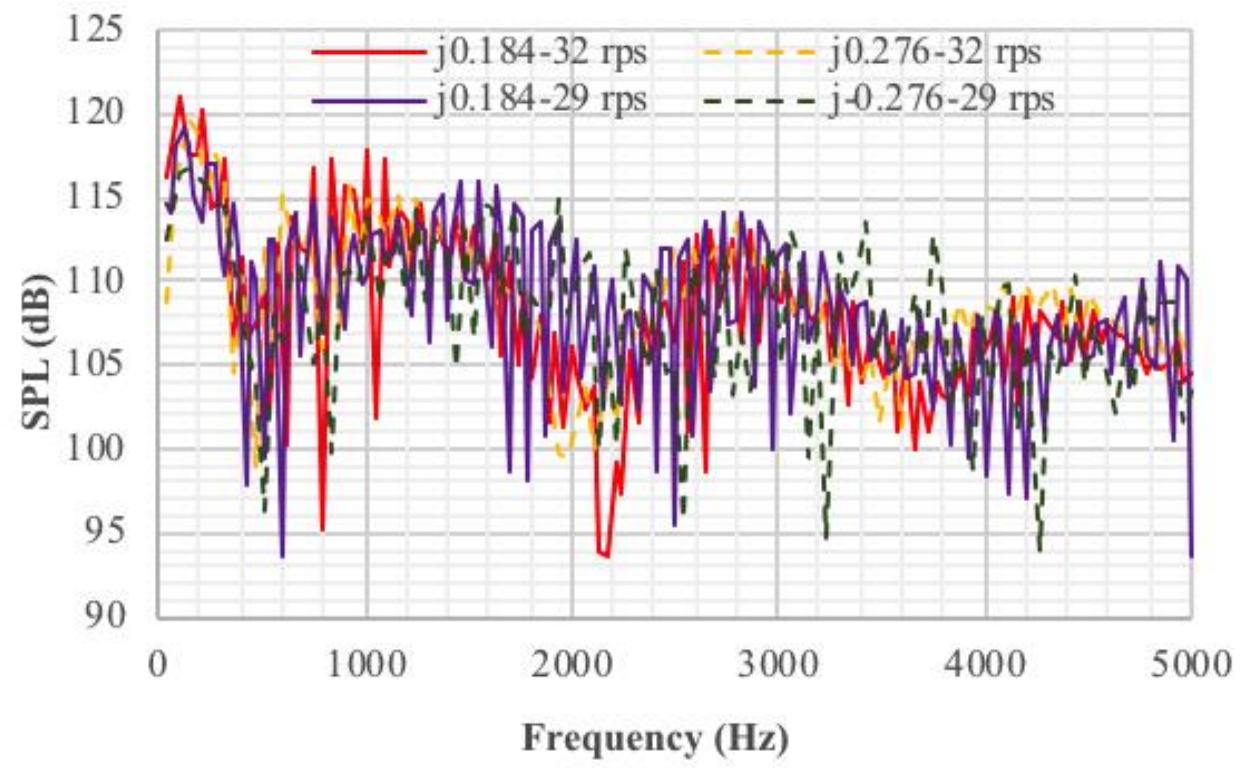

Figure 17: Noise prediction graph up to $5000 \mathrm{~Hz}(\mathrm{SPLs}(\mathrm{dB})$ for receiver 3 at propeller, $\mathrm{P}$ ref $(\mathrm{Pa})=$ $10^{-06}$ for $\mathrm{J}=0.184$ and $\mathrm{J}=0.276, \mathrm{~N}=29 \mathrm{rps}$ and $32 \mathrm{rps}, 50 \mathrm{kPa}$

\section{Conclusions}

This paper investigated the hydrodynamic and noise phenomenon of a propeller in non-cavitation and cavitation operating conditions. A finite volume based RANS solver has been used to evaluate the performance of these systems. The result of this paper shows that the numerical findings are in good agreement with the experimental data.

The experiment have been done using propeller speed of 29 and 32rps with flow velocity of 0.601$1.7664 \mathrm{~m} / \mathrm{s}$ for noise prediction. The result of experiments shows that the overall SPLs for hydrophone 3 is higher than hydrophone 1 and 2 since the higher turbulence and cavitation in the location of hydrophone 3 .

The noise of propeller at $\mathrm{J}=0.184-32 \mathrm{rps}$ is higher than the propeller at $\mathrm{J}=0.184-29 \mathrm{rps}$, in measurement in all the hydrophone. The noise of propeller at $\mathrm{J}=0.276-32 \mathrm{rps}$ is higher than the propeller at $\mathrm{J}=0.276-29 \mathrm{rps}$, in measurement in all the hydrophone.

The ranges of SPLs increase with the increasing of rotational speed of propeller, since the increasing of both parameters affected on the increasing of turbulence and cavitation. The obtained results can be used to optimize the operational parameter of derivate pattern of noise radiation at underwater vehicle. 


\section{Acknowledgements}

For the Ministry of Research, Technology and Higher Education of Indonesia was financially supported this works. This work was simulation numerically supported by the Chemical Engineering Department of the Sepuluh Nopember Institute of Technology Surabaya.

\section{References}

[1] Ffowcs Williams JE, Hawkings DL (1969) 'SoundGeneration by Turbulence and Surfaces in ArbitraryMotion'. Philosophical Transactions of the RoyalSociety A264: 321 -342.

[2] Seol, H., Suh, JC, \& Lee, S. (2002) 'Prediction of NonCavitating Underwater Propeller Noise'. J. Sound andVibration, 257(1), pp.131-156.

[3] Seol, H., Suh, JC. \& Lee, S. (2005) 'Development ofHybrid Method for the Prediction of UnderwaterPropeller Noise'. J. Sound and Vibration, 288(1),pp.345-360.

[4] Salvatore, F. \& Ianniello, S. (2003) 'Preliminary Resultson Acoustic Modelling of Cavitating Propellers'.Comp. Mechanics, 32, pp.291-300.

[5] Barbarino, M. \& Casalino, D. (2012) 'HybridAnalytical/Numerical Prediction of PropellerBroadband Noise in Time Domain'. Int. Jour. OfAeronautics, 11(2), pp.157-175.

[6] M. Cansın Özden. et al, Underwater Radiated Noise Prediction for a Submarine Propeller in Different Flow Conditions, A. Yücel Odabaşs Colloquium Series 1st International Meeting - Propeller Noise \& Vibration 6th - 7th November 2014, Istanbul, Turkey.

[7] Kawamura, T., Watanabe, T., Takekoshi, Y., Maeda, M., Yamaguchi, H. Numerical (2004) 'Simulation of Cavitating Flow around a Propeller' JSNA. 195.

[8] Li, D.-Q. (2006) 'Validation of RANS Predictions of OpenWater Performance of a Highly Skewed Propeller withExperiments'. Conference of Global Chinese Scholarson Hydrodynamics, Journal of Hydrodynamics, 18(3),Supplement, pp.520-528.

[9] ANSYS (2009)

[10]J.Sauer and G.H. Schnerr (2000), Unsteady cavitating Flow-A New Cavitation Model Based On a Modified Front Capturing Method and Bubble Dyanamics. Proceeding of FEDSM2000-11095,2000 ASME Fluids Engineering Summer Conference, June 11-15, 2000, Boston, Massachusetts, USA

[11]Weixing Yuan, Jürgen Sauer, and Günter H.Schnerr (2001), Modeling and computation of unsteady cavitation flows in injection nozzles.

[12]P.Roosen, OUnruh, and M. Behmann. (1996)., "Untersuchung und Modellierung des transienten Verhaltens von Kavitationserscheinungen bei ein- und mehrkomponentigen Kraftstoffen in schnell durchströmten Düsen, Report of the Institute for Technical Thermodynamics, RWTH Aachen (Univ. of Tech.), Germany, March 1996.

[13]Nurwidhi Asrowibowo, Mahendra Indiaryanto and Rina, "Optimization Design and Hydrodynamic Test on Propeller Mini Submarine”, Journal of Aeronautical-Science and Engineering, Vol.27, 20 Januari 2016. 